Its chemical properties are similar to those of the oxychloride.

In liquid form, above $42^{\circ}$, it is a powerful solvent, deporting itself in general as an oxidizing and brominating agent.

Madison, Wisconsin

[Contribution from the Muspratr Laboratory of Physical, and EllectroCHEMISTRY, UNIVERSITY OF LIVERPOOL]

\title{
THE EFFECT OF SUCROSE ON THE ACTIVITIES OF THE CHLORIDE AND HYDROGEN IONS
}

\author{
By J. W. Corran and W. C. M. Lewis
}

Received May 29, 1922

\section{The Effect of Sucrose on the Activity of the Chloride Ion in Tenth and Half Normal Solutions of Potassium Chloride}

In recent years, the measurement of the individual activity of an ion has been rendered possible by certain assumptions, first made by MacInnes. ${ }^{1}$

The first postulate was that the activities of the anion and cation in the same solution of an electrolyte may differ from one another; the second, that in solutions of potassium chloride, the activities of the anion and cation are equal; and the third, that in solutions of univalent chlorides of the same concentrations, the chloride ion has the same activity in every case. The second and third asstmptions have been shown by Harned,? to be true experimentally.

Noyes and MacInnes ${ }^{3}$ have utilized the values of the e.m.f.'s of the cells with and without transport containing potassium chloride, obtained by MacInnes and Parker, ${ }^{4}$ to calculate the activities of potassium chloride in solutions of different concentration, varying from 0.001 to $0.5 \mathrm{M}$. As a basis for the calculation of these relative activities the assumption was made that the activity coefficient: was identical with the conductivityviscosity ratio in very dilute solutions, and on this basis the activities in solutions up to $0.5 \mathrm{~N}$ potassium chloride were computed. By means of the second postulate of MacInnes, the activities of potassium chloride become identical with those of the chloride ion.

The present investigation consists of measurements of the activity of the chloride ion when the environment is changed by the use of sucrose solutions of different concentrations as solvent in place of pure water. The reason for the use of sucrose is that it is proposed to extend the measurements of the activities of ions, when the environment is changed, to the

1 MacInnes, This Journal, 41, 10836 (1919).

2 Harned, ibid., 42, 1808 (1920).

3 Noyes and MacInnes, ibid., 42, 239 (1920).

- MacInnes and Parker, ibid., 37, 1445 (1915). 
case of the hydrogen ion and to compare results with those obtained by means of another type of cell, in which sucrose has been used. Also, because much work has been done with sucrose in connection with the inversion process, a large amount of data with reference to sucrose solutions is available.

The type of cell used is almost identical with that used by MacInnes and Parker, ${ }^{4}$ i.e., the cell with transport, namely, $\mathrm{Ag}|\mathrm{AgCl}| \mathrm{KCl}$ (I) $\mathrm{KCl}+$ sucrose (II) $\mid \mathrm{AgCl} / \mathrm{Ag}$, in which the liquid-liquid potential difference is not annulled. The e.m.f. of this cell is given by the expression

$$
E=2 n_{R} \cdot \frac{R T}{F} \log \frac{\mathrm{Cl}_{\mathrm{I}}}{\mathrm{C} \mathrm{Cl}_{\mathrm{II}}}
$$

where $n_{K}$ is the transport number of the potassium ion and has the value 0.495 , and $\mathrm{Cl}_{\mathrm{I}}$ and $\mathrm{Cl}_{\mathrm{II}}$ represent the activities of the chloride ion.

The assumptions made by MacInnes are adhered to and further, for the present, to make calculations possible, it is assumed that the transport number of the potassium ion is the same in the presence of sucrose as in pure aqueous solutions. The latter is a rather bold assumption to make at this stage, but it is confirmed by the general nature of the results obtained.

\section{Experimental}

The potassium chloride and sucrose had already been used for exact e.m.f. work. The electrical instruments consisted of a Cambridge-Paul potentiometer, a sensitive mirror galvanometer, and a standard cell having an e.m.f. of 1.0183 volt at $20^{\circ}$ with a decrease of 0.00004 volt per degree rise in temperature. A constant temperature of $25^{\circ} \pm 0.05^{\circ}$ was attained by means of an electrically regulated thermostat, which was earthed. In order to eliminate external electrical effects, the potentiometer, galvanometer and accumulator rested on sheets of glass which were separated from a piece of sheet iron by means of paraffin wax. This piece of sheet iron was connected to earth.

The cell and electrodes were made as described by MacInnes and Parker, ${ }^{4}$ the electrode vessels being adapted according to the instructions of Cumming and Gilchrist ${ }^{5}$ in order to minimize diffusion at the liquid junctions.

In order to make certain that the cell was working correctly, several concentration cells of potassium chloride in aqueous solution were set up and the e.m.f.'s observed were compared with those obtained by other workers. The potassium chloride solutions were in all cases saturated with silver chloride before being used. The results of these measurements are shown in Table I.

${ }^{5}$ Cumming and Gilchrist, Trans. Faraday Soc., 9, 174 (1913). 


\section{TABLE I}

Measuremeints with Concentration Cells of Potassium Chloride

$\begin{array}{lllcc}C_{1} & C_{2} & E_{\text {obs. }} & E_{1} & E_{2} \\ 0.5 & 0.05 & 0.0535 & 0.0531 & 0.0536(\mathrm{M} .-\mathrm{P} .) \\ 0.5 & 0.1 & 0.0368 & 0.0369 & 0.0369(\mathrm{~F} .-\mathrm{M} .) \\ 1.0 & 0.1 & 0.0529 & 0.0527 & 0.0529(\mathrm{~F} .-\mathrm{M} .) \\ 2.0 & 0.5 & 0.0328 & 0.0325 & 0.0320(\mathrm{~F} .-\mathrm{M} .)\end{array}$

$C_{1}$ and $C_{2}$ represent the concentrations of salt, expressed in gramequivalents of salt per liter of solution. Under $E_{\text {obs, }}$, are the results obtained by means of the present cell. $E_{1}$ represents the values of the e.m.f.'s calculated from the activities of potassium chloride given in the table of Noyes and MacInnes, ${ }^{3}$ while under $E_{2}$ are the values obtained by other observers. M. - P. is an abbreviation for MacInnes and Parker, while F. - M. stands for Fales and Mudge. ${ }^{6}$ The latter observers found the following potentials for different calomel half elements.

$\begin{array}{llllll}\text { Conc. of } \mathrm{KCl} \text { (molar).. } & 0.1 & 0.5 & 1.0 & 2.0 & 3.0 \\ \text { Electrode p. d........ } & 0.6177 & 0.5808 & 0.5648 & 0.5488 & 0.5377\end{array}$

From these results $E_{2}$ (F. - M. . are found by difference. As $E_{\text {obs. was }}$ found to agree very well with $E_{1}$ and $E_{2}$, it was concluded that the cell was working satisfactorily.

A series of cells was now set up in which the concentrations of potassium chlorides in the two compartments were respectively $0.5 \mathrm{~N}$ and $0.1 \mathrm{~N}$ (moles of potassium chloride per liter of solution). Into the latter compartment were introduced various amounts of sucrose, varying from 0 to $70 \%$. The e.m.f.'s of these cells were measured at $25^{\circ}$.

The activity of the chloride ion in $0.5 \mathrm{~N}$ potassium chlo:ide solution was taken to be $0.324 .^{7}$ Hence the expression used for the computation of activities from the observed e.m.f.'s becomes

where $a_{\mathrm{Cl}_{0.1},}$ is the required activity.

$$
E=0.99 \times 0.059 \log _{10} \frac{0.324}{a_{\mathrm{Cl}} .1}
$$

In Table II, the values of the e.m.f.'s observed are given, and in the last column are the activities of the chloride ion in the $0.1 \mathrm{~N}$ solution in the presence of sticrose.

It will be observed that the e.m.f. of the cell decreases up to $50 \%$ sucrose solutions by a fairly constiant amount, after which it decreases by a rather larger amount. The effect of the sucrose is to increase the activity of the chloride ion from 0.0760 when no sucrose is present, to 0.126 when there is $70 \%$ of sucrose present.

${ }^{6}$ Fales and Mudge, This Journal, 42, 2434 (1920).

${ }^{7}$ Ref. 3. Noyes and Maclnnes expressed their $\mathrm{KCl}$ concentrations as moles per $1000 \mathrm{~g}$. of water, whereas in the present investigation concentrations are expressed as moles per $1000 \mathrm{cc}$. of solution. Due allowance has been made for the change in units. 


\section{TABLE II}

Activities of Chloride Ion in Tenth Normal Solution in the Presence of SUCROSE

Sucrose

per $100 \mathrm{cc}$.

of solution

G.

0

E.m.f. obs. (volts)

\begin{tabular}{llll}
\hline 0.0368 & 0.0368 & 0.0368 & 0.0368 \\
0.0353 & 0.0351 & 0.0352 & 0.0352 \\
0.0336 & 0.0334 & 0.0335 & 0.0334 \\
0.0315 & 0.0318 & 0.0319 & 0.0319 \\
0.0298 & 0.0300 & 0.0302 & 0.0301 \\
0.0279 & 0.0281 & 0.0283 & 0.0281 \\
0.0254 & 0.0260 & 0.0264 & 0.0262 \\
0.0234 & 0.0242 & 0.0244 & 0.0240
\end{tabular}

Av.

$a_{\mathrm{Cl} l .1}$

$0.0368 \quad 0.0760$

0.0352

0.0809

20

30

40

50

60

70

0.0234

0.0242

0.0244

0.0335

0.0865

$0.0319 \quad 0.0921$

$0.0300 \quad 0.0993$

$0.0281 \quad 0.1070$

$\begin{array}{ll}0.0261 & 0.1158\end{array}$

The cell was also used to determine the change in activity of the chloride ion in $0.5 \mathrm{~N}$ solutions of potassium chloride caused by the presence of sucrose. The value of the activity in $0.1 \mathrm{~N}$ solution was taken to be 0.0760 , whence the expression from which the activities were determined becomes

$$
E=0.99 \times 0.059 \log \frac{a_{\mathrm{Cl} 10.5}}{0.0760}
$$

where $a_{\mathrm{Cl}_{0.5}}$ is the required activity. In Table III are the values of the observed e.m.f.'s, together with the activities of the chloride ion calculated from these values.

\section{TABLE III}

Actrvities of Chloride Ion in Half Normal Solution in the Presence of Sucrose Sucrose

per $100 \mathrm{cc}$.

of solution

$$
\text { G. }
$$

E.m.f. obs.

$\begin{array}{llll}0.0368 & 0.0368 & 0.0368 & 0.0368\end{array}$.

Av.

$a_{\mathrm{Cl} 0,5}$

0

0.0385

0.0384

0.0384

0.0384

0.0368

0.0324

20

0.0401

0.0401

0.0402

0.0401

0.0384

0.3452

0.0417

0.0418

0.0418

0.0418

0.0401

0.3692

40

0.0435

0.0433

0.0434

0.0435

0.0418

0.3950

0.0453

0.0454

0.0456

0.0454

0.0435

0.4222

60

0.0471

0.0475

0.0475

0.0474

0.0497

0.0495

0.0454

0.4551

0.0500

0.0495

0.0474

0.4925

0.5370

The fractional increase in the activity of the chloride ion in $0.5 \mathrm{~N}$ solution, as shown by Table III, is almost identical with that in the case of $0.1 N$ solution.

\section{Discussion of Results}

The question of the cause of the increase in activity of the chloride ion in the presence of sucrose at once arises. In the first place the presence of sucrose means that there will be a decrease in the total amount of water in the solution, since the concentration of salt is expressed as moles per 
liter of solution. This decrease in the total amount will certainly affect the activity, as the effective concentration of the potassium chloride will be increased. In addition to the decrease in the total water, there will be a decrease in the free water due to the hydration of sucrose. A sucrose molecule possesses, on the average, 4 molecules of water of hydration, a result obtained by Moran and Lewis in this laboratory. ${ }^{8}$

The point to be settled is whether the rise in activity of the chloride ion in sucrose solutions can be accounted for by means of one or both of these effects. In order to do this, the compositions of the solutions by weight were found and from these compositions the number of mols of potassium chloride per $1000 \mathrm{~g}$. of total water and free water were determined in each case. From the tables of Noyes and MacInnes, the activity coefficients corresponding to these effective concentrations were obtained, whence the activities were calculated by multiplying activity coefficients by effective concentrations.

Table IV shows the total water and free water per $1000 \mathrm{cc}$. of sucrose solutions containing $0.1 \mathrm{~mol}$ of potassium chloride. Table IV $a$ contains the effective concentrations, that is, the number of moles of salt per 1000 g. of water, calculated in terms of total water, together with the corresponding activities of the chloride ion. Table IVb gives the same quantities, calculated in terms of free water. In Table IVc, a comparison of the observed and calculated activities is made.

Tables $\mathrm{V}, \mathrm{V} a, \mathrm{~V} b, \mathrm{~V} c$ show the corresponding data for $0.5 \mathrm{~N}$ solutions.

It will be noticed that no allowance has been made for the hydration of potassium chloride itself.

The following tables show that the values of $a_{1}$, that is, the activities calculated on the assumption that the water of hydration of sucrose is not available as solvent for the potassium chloride, diverge from $a_{\mathrm{obs}}$, as the concentration increases, being about $33 \%$ greater in the case of $70 \%$ sucrose solutions.

\section{TABLE IV}

Composimtons of $1000 \mathrm{Cc}$. of Solution Containing 0.1 Mol of Potassium Chioride

Sucrose

G.

0

100

200

300

400

500

600

700

\section{Total water}

G.

995.05

933.0

871.6

809.5

748.0

681.7

618.8

554.1
Water of hydration

G.

0

21

42

63

84

105

126

147
Free water

G.

995.05

912.0

829.6

746.5

664.0

576.7

492.8

407.1

${ }^{8}$ As yet unpublished. 


\section{TABLE IV $a$}

Concentration of Potassium Chloride in Terms of Total Water Present

$\begin{array}{cccc}\text { Sucrose } & \begin{array}{c}\text { Total water } \\ \text { per liter of } \\ \text { solution }\end{array} & \begin{array}{c}\mathrm{KCl} \text { per } 1000 \\ \text { g. of water } \\ \text { Mols }\end{array} & \begin{array}{c}\text { Activity } \\ \text { calculated }\end{array} \\ 0 & 9 . & 0.1005 & 0.07 \\ 10 & 995.05 & 0.1072 & 0.0749 \\ 20 & 933.0 & 0.1147 & 0.0795 \\ 30 & 871.6 & 0.1235 & 0.0850 \\ 40 & 809.5 & 0.1337 & 0.0909 \\ 50 & 748.0 & 0.1467 & 0.0981 \\ 60 & 681.7 & 0.1616 & 0.1068 \\ 70 & 618.8 & 0.1805 & 0.1168 \\ & 554.1 & & 0.1289\end{array}$

TABLE IV $b$

Concentration of Potassium Chloride in Terms of Free Water Present

\section{Free water} per liter of

Sucrose

$\%$

0

10

20

30

40

50

60

70 solution

G.

995.05

912.0

829.6

746.5

664.0

576.7

492.8

407.1
$\mathrm{KCl}$ per 1000

$\mathrm{g}$. of water

Mols

0.1005

0.1096

0.1205

0.1339

0.1506

0.1734

0.2029

0.2456
Activity calculated

$a_{1}$

0.0749

0.0815

0.0892

0.0981

0.1095

0.1240

0.1431

0.1683

TABLE IV $c$

Comparison of Calculated and Observed Activities

$\begin{array}{cccc}\begin{array}{c}\text { Sucrose } \\ \%\end{array} & \begin{array}{c}a_{1}, \text { in terms of } \\ \text { free water }\end{array} & \begin{array}{c}a_{2}, \text { in terms of } \\ \text { total water }\end{array} & a_{\text {obs. }} \\ 0 & 0.0749 & 0.0749 & 0.0760 \\ 10 & 0.0815 & 0.0795 & 0.0809 \\ 20 & 0.0892 & 0.0850 & 0.0865 \\ 30 & 0.0981 & 0.0909 & 0.0921 \\ 40 & 0.1095 & 0.0981 & 0.0993 \\ 50 & 0.1240 & 0.1068 & 0.1070 \\ 60 & 0.1431 & 0.1168 & 0.1158 \\ 70 & 0.1683 & 0.1289 & 0.1258\end{array}$

TABLE V

Compositions of $1000 \mathrm{CC}$. of Solutions Containing 0.5 Mol of Potassium Chloridf

$\begin{array}{cccc}\text { Sucrose } & \text { Total water } & \begin{array}{c}\text { Water of } \\ \text { hydration } \\ \text { G. }\end{array} & \begin{array}{c}\text { Free water } \\ \text { G. }\end{array} \\ 0 & 983.1 & 0 & 98.1 \\ 100 & 921.1 & 21 & 900.1 \\ 200 & 859.0 & 42 & 817.0 \\ 300 & 796.9 & 63 & 733.9 \\ 400 & 734.4 & 84 & 650.4 \\ 500 & 670.0 & 105 & 565.0 \\ 600 & 606.5 & 126 & 480.5 \\ 700 & 543.5 & 147 & 396.5\end{array}$


TABLE V $a$

Concentration of Potassium Chloride in Terms of Total Water Present

$\begin{array}{cccc}\begin{array}{c}\text { Sucrose } \\ \%\end{array} & \begin{array}{c}\text { Total water } \\ \text { per liter of } \\ \text { solution } \\ \text { G. }\end{array} & \begin{array}{c}\text { KCl per } 1000 \\ \text { g. of water } \\ \text { Mols }\end{array} & \begin{array}{c}\text { Activity } \\ \text { calculated }\end{array} \\ 0 & 983.1 & 0.5085 & 0.3239 \\ 10 & 921.1 & 0.543 & 0.3441 \\ 20 & 859.0 & 0.582 & 0.3667 \\ 30 & 796.9 & 0.627 & 0.3919 \\ 40 & 734.4 & 0.681 & 0.4222 \\ 50 & 670.0 & 0.746 & 0.4576 \\ 60 & 606.5 & 0.824 & 0.5007 \\ 70 & 543.5 & 0.920 & 0.5520\end{array}$

TABLE V $b$

Concentration of Potassium Chloride in Terms of Free Water Present

$\begin{array}{cccc}\text { Sucrose } & \begin{array}{c}\text { Free water } \\ \text { per liter of } \\ \text { solution } \\ \text { G. }\end{array} & \begin{array}{c}\mathrm{KCl} \text { per } 1000 \\ \text { g. of water } \\ \text { Mols }\end{array} & \begin{array}{c}\text { Activity } \\ \text { calculated }\end{array} \\ 0 & 983.1 & 0.5085 & 0.3239 \\ 10 & 900.1 & 0.555 & 0.3510 \\ 20 & 817.0 & 0.612 & 0.3837 \\ 30 & 733.9 & 0.681 & 0.4222 \\ 40 & 650.4 & 0.769 & 0.4699 \\ 50 & 565.0 & 0.885 & 0.5337 \\ 60 & 480.5 & 1.040 & 0.6136 \\ 70 & 396.5 & 1.260 & 0.7402\end{array}$

TABLE $V C$

Comparison of Calculateid and OBSERVEd Activities

$\begin{array}{cccc}\begin{array}{c}\text { Sucrose } \\ \%\end{array} & \begin{array}{c}a_{1}, \text { in terms of } \\ \text { free water }\end{array} & \begin{array}{c}a_{2} \text {, in terms of } \\ \text { total water }\end{array} & a_{\text {obs. }} \\ 0 & 0.3239 & 0.3239 & 0.3240 \\ 10 & 0.3510 & 0.3441 & 0.3452 \\ 20 & 0.3837 & 0.3667 & 0.3692 \\ 30 & 0.4222 & 0.3919 & 0.3950 \\ 40 & 0.4699 & 0.4222 & 0.4222 \\ 50 & 0.5337 & 0.4576 & 0.4551 \\ 60 & 0.6136 & 0.5007 & 0.4925 \\ 70 & 0.7402 & 0.5520 & 0.5370\end{array}$

On the other hand, $a_{2}$, the values calculated on the assumption that the activity of the chloride ion is only affected by decrease in the total water, agrees satisfactorily with the observed activities. The values for $70 \%$ sucrose show about $2 \%$ difference, but this is probably due to experimental error. There is a possibility that this difference is due to a change in the transport number of the potassium ion in the presence of $70 \%$ sucrose, due only to the presence of sucrose, for Washburn ${ }^{9}$ has shown that

${ }^{9}$ Washburn, This JournaI, 31, 322 (1909). 
the transport number of potassium in potassium chloride solutions has a constant value up to $1.3 \mathrm{~N}$ solutions, whereas the highest effective concentration reached in the present case is $0.920 \mathrm{~mol}$ per $1000 \mathrm{~g}$. of water. It is proposed in a later publication to compare the present results with those obtained by means of a cell without transport. ${ }^{4}$

Neglecting the small differences which exist, it is improbable that the close agreement between $a_{2}$ and $a_{\mathrm{obs}}$ is merely a coincidence. It means that, besides being soluble in the free water, the chloride and potassium ions are also soluble in the water of hydration of sucrose. That is, beyond taking up space previously occupied by water, the sucrose behaves as an inert substance with respect to these ions.

Apart from these direct conclusions, the close agreement between $a_{2}$ and $a_{\text {obs. }}$ furnishes justification for certain assumptions that have been made. The first is that the activity of the potassium ion is equal to that of the chloride in the presence of sucrose as well as in pure aqueous solutions. In view of the fact that the sucrose merely appears to take up space in the solution, its effect on the potassium and chloride ions will be the same. Hence, the extension of MacInnes' assumption to sucrose solutions is admissible.

Similarly, justification is furnished for the assumption of the constancy of the transport number of the potassium ion. Sucrose solutions have a much greater viscosity than water, and increasing viscosity affects the absolute velocity of the ions. Therefore, it follows that if the transport numbers are constant, the sucrose has the same effect on the mobilities of the potassium and chloride ions.

Green ${ }^{10}$ has found that in solutions of potassium chloride in the presence of sucrose, the following relation is true, $\lambda . \eta^{0.7}=$ a constant, where $\Lambda$ is the equivalent conductivity and $\eta$ is the viscosity of the solution. In view of the constancy of the transport numbers of the potassium and chloride ions in the presence of sucrose, it follows that the product $n_{\mathrm{Cl}} \cdot \Lambda \cdot \eta^{0.7}$ is a constant, where $n_{\mathrm{Cl}}$ represents the transport number of the chloride ion. MacInnes ${ }^{11}$ has found that this product is a constant when the solvent is pure water and the solute is potassium chloride. Hence, one is able to extend MacInnes' relation to the case in which the solvent consists of sucrose solutions.

\section{The Effect of Sucrose on the Activity of the Hydrogen Ion in Tenth Normal Solutions of Hydrochloric Acid}

As already mentioned, MacInnes ${ }^{1}$ has made the assumption that in solutions of univalent chlorides of the same concentration, the activity of the chloride ion has the same value in every case, irrespective of the associated cation. Harned ${ }^{2}$ verified this assumption experimentally.

${ }^{10}$ Green, J. Chem. Soc., 93, 2023 (1908).

I1 MacInnes, This JourNaL, 43, 1217 (1921). 
By using the cell with transport, similar to that used in Part I, but substituting hydrochloric acid for potassium chloride, it is possible to measure the activity of the hydrogen ion, knowing that of the chloride ion. The e.m.f. of the cell, $\mathrm{Ag}|\mathrm{AgCl}| \mathrm{HCl}$ (I) $\mid$ sat. $\mathrm{KCl} \mid \mathrm{HCl}$ (II) $|\mathrm{AgCl}| \mathrm{Ag}$, is given by the expression

$$
E=\frac{R T}{F} \log \frac{\sqrt{\mathrm{HI} \times \mathrm{ClI}_{1}}}{\sqrt{\mathrm{HII}_{\mathrm{II}} \mathrm{ClI}}}
$$

where $\mathrm{H}_{\mathrm{I}}$ and $\mathrm{Cl}_{\mathrm{I}}$ are the hydrogen and chloride ion activities, respectively, in Solution $\mathrm{I}$ and $\mathrm{H}_{\mathrm{II}}$ and $\mathrm{Cl}_{\mathrm{II}}$ the activities in Solution II, the liquid-liquid potential difference being annulled by means of saturated potassium chloride solution. ${ }^{12}$

Knowing the value of the geometric mean of the activities of the hydrogen and chloride ions in one of the solutions, the e.m.f. of the cell determines the other value for the geometric mean. A knowledge of the chloride-ion activity in the latter case enables one to calculate the hydrogen-ion activity.

In the present case, the concentrations of hydrochloric acid used in the cell are $0.5 \mathrm{~N}$ and $0.1 \mathrm{~N}$, respectively. In the compartment containing $0.1 \mathrm{~N}$ acid, the solvent consists of solutions of sucrose in water ranging from 0 to $70 \%$, as in the previous case. The value for the geometric mean of the hydrogen- and chloride-ion activities in the case of $0.5 \mathrm{~N}$ aqueous solution of hydrochloric acid was taken to be $0.3911^{7}$. Hence the expression from which the activities of hydrochloric acid were calculated becomes

$$
E=0.059 \log \frac{0.3911}{a_{\mathrm{EOl}}}
$$

where $a_{\mathrm{HCl}}$ represents the geometric mean of the hydrogen- and chlorideion activities in the $0.1 \mathrm{~N}$ solution. The liquid-liquid potential difference was annulled by means of saturated potassium chloride solution and when sucrose was present in one side, some was added to the saturated potassium chloride such that the concentration of sucrose in the bridge was about half of what it was in the cell itself.

\section{Experimental}

The apparatus was similar to that already described.

In Table VI are given the values for the e.m.f.'s of the cells with various concentrations of sucrose. The measurements were carried out at $25^{\circ}$ as were the previous measurements. In the last column of Table VI are given the geometric means of the activities of the two ions, as calculated from the observed e.m.f. values by means of the above expression. In Table VII, the activities of the chloride ion in the solutions are shown in Col. 2, the geometric-mean activities in Col. 3, while in Col. 4 are given the hydrogen-ion activities, calculated from the values in Cols. 2 and 3.

12 Fales and Vosburgh, This Journat, 40, 1291 (1918). 


\begin{tabular}{|c|c|c|c|c|c|c|c|}
\hline \multirow{2}{*}{$\begin{array}{l}\text { Sucrose } \\
\% \\
0\end{array}$} & \multicolumn{4}{|c|}{ E.m.f. in volts } & $\begin{array}{c}\text { Val,UES } \\
\text { Av. }\end{array}$ & $\begin{array}{c}\text { Smoothed } \\
\text { values }\end{array}$ & \multirow{2}{*}{$\begin{array}{l}\text { Geometric- } \\
\text { mean activities }\end{array}$} \\
\hline & 0.0406 & 0.0408 & 0.0409 & 0.0407 & 0.0408 & 0.0408 & \\
\hline 10 & 0.0381 & 0.0380 & 0.0380 & 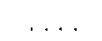 & 0.0380 & 0.0380 & 0.0888 \\
\hline 20 & 0.0353 & 0.0346 & 0.0348 & $\ldots$ & 0.0349 & 0.0349 & 0.1002 \\
\hline 30 & 0.0326 & 0.0323 & 0.0322 & $\ldots$ & 0.0323 & 0.0320 & 0.1121 \\
\hline 40 & 0.0292 & 0.0288 & 0.0288 & $\ldots$ & 0.0288 & 0.0289 & 0.1266 \\
\hline 50 & 0.0263 & 0.0266 & 0.0256 & $\ldots$ & 0.0260 & 0.0257 & 0.1434 \\
\hline 60 & 0.0220 & 0.0226 & 0.0218 & 0.0222 & 0.0220 & 0.0222 & 0.1644 \\
\hline 70 & 0.0186 & 0.0190 & 0.0186 & 0.0185 & 0.0186 & 0.0186 & 0.1892 \\
\hline \multicolumn{8}{|c|}{ TABLE VII } \\
\hline & 要 & \multicolumn{2}{|c|}{0.0760} & \multicolumn{2}{|c|}{0.0796} & \multicolumn{2}{|c|}{0.0834} \\
\hline & 10 & \multicolumn{2}{|c|}{0.0809} & \multicolumn{2}{|c|}{0.0888} & \multicolumn{2}{|c|}{0.0974} \\
\hline & 20 & \multicolumn{2}{|c|}{0.0865} & \multicolumn{2}{|c|}{0.1002} & \multicolumn{2}{|c|}{0.1161} \\
\hline & 30 & \multicolumn{2}{|c|}{0.0921} & \multicolumn{2}{|c|}{0.1121} & \multicolumn{2}{|c|}{0.1367} \\
\hline & 40 & \multicolumn{2}{|c|}{0.0993} & \multicolumn{2}{|c|}{0.1266} & \multicolumn{2}{|c|}{0.1614} \\
\hline & 50 & \multicolumn{2}{|c|}{0.1070} & \multicolumn{2}{|c|}{0.1434} & \multicolumn{2}{|c|}{0.1923} \\
\hline & 60 & \multicolumn{2}{|c|}{0.1158} & & \multicolumn{2}{|c|}{0.2335} \\
\hline & 70 & \multicolumn{2}{|c|}{0.1258} & \multicolumn{2}{|c|}{0.1892} & \multicolumn{2}{|c|}{0.2847} \\
\hline
\end{tabular}

The values for the geometric-mean activities show that both the hydrogen-ion activities and the geometric-mean activities are increased by the addition of sucrose, but that the increase in the case of the hydrogen ion is much more pronounced.

\section{Discussion of Results}

In the computation of hydrogen-ion activities by the direct method, that is, by means of the cell $\mathrm{Hg}\left|\mathrm{Hg}_{2} \mathrm{Cl}_{2}\right| \mathrm{KCl} N \mid \mathrm{KCl}$ sat. $|\mathrm{HCl}| \mathrm{H}_{2}$, the assumption is generally made that the hydrogen electrode measures the hydrogen-ion activity and not the geometric mean of the hydrogen-and chloride-ion activities. Such an assumption needs experimental verification.

A comparison of results obtained by means of the silver-silver chloride concentration cell, shown in Table VII, with those obtained by the direct method, in which solutions of hydrochloric acid in the presence of sucrose have been used, furnishes a convenient method of verifying this assumption. Measurements by means of the direct method have been carried out in this laboratory by Mr. T. Moran, the solvent being solutions of sucrose, and the solute hydrochloric acid of $0.1 \mathrm{~N}$ concentration. The value for the normal calomel electrode was taken to be 0.5648 volt at $25^{\circ}$. The activity, assumed to be hydrogen-ion activity, was calculated by means of the expression

$$
E=E_{0}+0.059 \log a_{\mathrm{H}}
$$

where $E$ was the observed potential of the hydrogen electrode and $E_{0}$ was the potential when the hydrogen-ion activity was unity. 
In the last column of Table VIII are given the values of the activity measured by Moran using the hydrogen electrode, while in Cols. 2 and 3 are shown the geometric means and hydrogen-ion activities, respectively, as recorded in Table VII of the present paper, using the silversilver chloride concentration cell.

TABLE VIII

Comparison with Moran's Values

Sucrose
$\%$
0
10
20
30
40
50
60
70

Geometric-mean activities

$\begin{array}{cc}a_{\mathrm{H}} & a_{\mathrm{H}} \text { (Moran) } \\ 0.083 & 0.080 \\ 0.097 & 0.096 \\ 0.116 & 0.115 \\ 0.137 & 0.139 \\ 0.161 & 0.167 \\ 0.192 & 0.200 \\ 0.234 & 0.240 \\ 0.285 & 0.288\end{array}$

It is evident from the above results that the activities measured by the hydrogen electrode correspond almost exactly with the individual hydrogen-ion activities obtained from the silver-silver chloride concentration cell, employing MacInnes' postulate regarding the independent activity of the chloride ion in solutions of univalent chlorides of the same concentration. In view of the different methods by which the activities have been computed, one cannot hope for exact agreement. Therefore, the deciding factor lies not so much in the absolute values, although these are distinct enough to make a decision possible, as in the fractional rise in the activity of the presence of sucrose. A glance at the table shows that the hydrogen electrode measures, beyond doubt, the hydrogen-ion activity and not the geometric mean of the activities of the hydrogen ion and the anion.

\section{Summary}

1. The effect of sucrose on the activity of the chloride ion in $0.1 \mathrm{~N}$ and $0.5 \mathrm{~N}$ potassium chloride lolutions has been studied by means of the cell $\mathrm{Ag}|\mathrm{AgCl}| \mathrm{KCl}\left(c_{1}\right) \mid \mathrm{KCl}\left(c_{2}\right)+$ Sucrose $|\mathrm{AgCl}| \mathrm{Ag}$. It has been found that the increase in activity could be accounted for by simply allowing for the decrease in the total water present in the solutions; that is, the potassium and chloride ions are soluble in the water of hydration of the sucrose.

2. The effect of sucrose on the activity of the hydrogen ion in $0.1 \mathrm{~N}$ hydrochloric acid has also been studied, using the MacInnes assumption of the independent activity of the chloride ion in solutions of chlorides of the same concentration. 
3. It was demonstrated by means of a comparison between the hydrogen-ion activities, obtained in the present investigation, and the values obtained with a hydrogen electrode, that the hydrogen electrode measures the hydrogen-ion activity and not the geometric mean of the activities of the hydrogen ion and the accompanying anion.

One of the authors of this paper (J.W. C.) wishes to express his thanks to the Department of Scientific and Industrial Research of the British Government, for a grant which enabled the research to be performed.

LIVERPOOL, ENGLAND

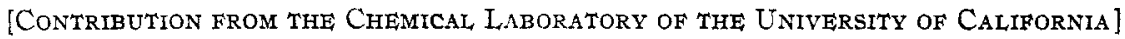
TEMPERATURE COEFFICIENT OF ELECTROMOTIVE FORCE OF GALVANIC CELLS AND THE ENTROPY OF REACTIONS

\section{By Roscoe H. Gerke}

Received June 5, 1922

The third law of thermodynamics in the limited form given by Lewis and Gibson ${ }^{1}$ is becoming regarded as an exact law of nature. These authors have calculated the entropy of the elements and compounds, ${ }^{2}$ for which heat-capacity data were available. They also tested the validity of the third law of thermodynamics by comparing the entropy change in a chemical reaction calculated on the one hand from heatcapacity data, and on the other hand from electromotive-force and thermochemical data. The discrepancies found amounted to over two entropy units on the average, but these were no greater than was to be expected, due to the inaccuracy of available calorimetric data.

The purpose of this investigation is to subject the third law of thermodynamics to a more rigorous test through more exact determination of entropy and heat content changes in a number of reactions. Such data can be determined with greater accuracy by a study of electromotive force of galvanic cells and its change with the temperature.

\section{Experimental Considerations}

By use of the equation $\frac{\mathrm{d} E}{\mathrm{~d} T}=\frac{\Delta S}{n f}$, and by the Gibbs-Helmholtz equation, $\frac{\Delta H}{n f}=-E+T\left(\frac{\mathrm{d} E}{\mathrm{~d} T}\right)$, the entropy change and the heat content change, respectively, may be calculated.

If the desired accuracy for the entropy change per equivalent is 0.10 calorie per degree, which corresponds to an accuracy of 30.0 calories for the change of heat content, the temperature coefficient of electromotive

${ }^{1}$ Lewis and Gibson, This Journal, 42, 1533 (1920).

2 Lewis and Gibson, ibid., 39, 2554 (1917). 